\title{
Effect of lifestyle intervention plus rosiglitazone or placebo therapy on left ventricular mass assessed with cardiovascular magnetic resonance in the metabolic syndrome
}

\author{
Stijntje D Roes, Reza A Dehnavi, Jos JM Westenberg, Hildo J Lamb, Bart JA Mertens, Jouke T Tamsma and \\ Albert de Roos*
}

\begin{abstract}
Background: To evaluate the effect of lifestyle intervention in conjunction with rosiglitazone or placebo therapy on left ventricular (LV) mass, using cardiovascular magnetic resonance (CMR) in the metabolic syndrome.

Methods: The present study was a pre-specified substudy of a double-blind randomized controlled trial evaluating the effect of lifestyle intervention in conjunction with rosiglitazone or placebo therapy on carotid artery atherosclerosis in the metabolic syndrome. From this original study population, 10 subjects from the placebo group and 10 from the rosiglitazone group were randomly selected. At baseline and follow-up (52 weeks), clinical and laboratory measurements were assessed and a CMR-examination was performed to evaluate LV mass indexed for body surface area (LV mass-I). Subsequently, the effect of therapy (rosiglitazone vs. placebo) and clinical and laboratory variables on LV mass-I was evaluated.
\end{abstract}

Results: In both groups, body mass index, waist circumference, systolic and diastolic blood pressure significantly decreased during follow-up. Interestingly, LV mass-I significantly decreased in the placebo group $\left(48.9 \pm 5.3 \mathrm{~g} / \mathrm{m}^{2}\right.$ vs. $44.3 \pm 5.6 \mathrm{~g} / \mathrm{m}^{2}, \mathrm{p}<0.001$ ) indicating reverse remodeling, whereas LV mass-I remained unchanged in the rosiglitazone group (54.7 $\pm 9.9 \mathrm{~g} / \mathrm{m}^{2}$ vs. $\left.53.7 \pm 9.2 \mathrm{~g} / \mathrm{m}^{2}, \mathrm{p}=0.3\right)$. After correction for systolic and diastolic blood pressure and triglyceride, the kind of therapy (rosiglitazone vs. placebo) remained the only significant predictor of LV mass-I reduction.

Conclusions: Lifestyle intervention resulted in a reduction of LV mass-I in the metabolic syndrome, indicating reverse remodeling. However, rosiglitazone therapy may have inhibited this positive reverse remodeling.

Trial registration: Current Controlled Trials ISRCTN54951661.

\section{Background}

The metabolic syndrome is a clustering of cardiovascular risk factors including abnormalities in glucose and lipid metabolism, abdominal obesity and hypertension [1], and is associated with increased risk of cardiovascular morbidity and mortality $[2,3]$. Although the exact pathophysiologic mechanism underlying the metabolic syndrome is still unclear, insulin resistance is believed to play a central role in the development of the metabolic

\footnotetext{
* Correspondence: a.de_roos@lumc.nl

Departments of Radiology, Endocrinology and Medical Statistics, Leiden University Medical Center, Albinusdreef 2, 2333 ZA Leiden, The Netherlands
}

syndrome $[1,4]$. Intensive lifestyle intervention by exercise and weight loss has beneficial effects on cardiovascular outcome in these patients. Also, pharmacological agents have been developed to reduce insulin resistance [5].

Peroxisome-proliferator-activated receptors (PPARs) regulate gene expression in response to ligand binding [5-7]. Thiazolidinediones (rosiglitazone, pioglitazone and troglitazone) represent a group of insulin sensitizing agents that can act as such ligands of the nuclear transcription factor PPAR- $\gamma$ [5]. After ligand binding, PPARs undergo specific conformational changes that allow for 
the recruitment of coactivator proteins [8]. Ligands differ in their ability to interact with coactivators, which explains the various biologic responses observed $[6,7]$. Clinical studies have shown that thiazolidinediones e.g. lower blood glucose levels by enhancing hepatic and peripheral glucose uptake and increase free fatty acid uptake and storage in adipose tissue (thereby decreasing free fatty acid uptake in other tissues) [5,9].

Previous studies revealed that patients with the metabolic syndrome often present with increased left ventricular (LV) mass (and LV hypertrophy) [10,11]. The Framingham Heart Study evaluated LV mass using echocardiography in relation to long-term clinical outcome, and observed that an increase in LV mass is an independent predictor of clinical events, including death, attributable to cardiovascular disease [12].

The effect of thiazolidinediones on LV mass has been studied previously in experimental and clinical settings, but is however still unclear [13-17]. These clinical studies used 2-dimensional echocardiography to assess LV function and LV mass $[15,17]$. Cardiovascular magnetic resonance (CMR) however, is a highly reproducible technique allowing for more accurate measurement of LV mass, enabling reduction of sample size [18].

Accordingly, the purpose of the present study was to evaluate the effect of lifestyle intervention in conjunction with rosiglitazone or placebo therapy on LV mass using CMR in subjects with the metabolic syndrome.

\section{Methods}

The present study was a pre-specified substudy of a double-blind randomized controlled trial evaluating the effect of lifestyle in conjunction with rosiglitazone or placebo therapy on carotid artery atherosclerosis in subjects with the metabolic syndrome (Rosiglitazone versUs placeBo on the prevENtion of progression of atheroSclerosis, RUBENS trial).

For this trial, 116 Caucasian male subjects with increased waist circumference $(\geq 94 \mathrm{~cm})$ and elevated CRP levels $(\geq 1.8 \mathrm{mg} / \mathrm{L})$, and two other metabolic syndrome criteria according to the International Diabetes Federation criteria [19] were selected. Exclusion criteria included type 2 diabetes (fasting blood glucose $\geq 7$ $\mathrm{mmol} / \mathrm{l}$ ), manifest cardiovascular disease, use of statins, steroids or non-steroidal anti-inflammatory drugs at baseline, heart failure (New York Heart Association class I or higher), QTc time interval of $450 \mathrm{~ms}$ or longer on baseline electrocardiogram (ECG), primary dyslipidemias, presence of potential hepatic disease (i.e. subjects with alanine aminotransferase, total bilirubin, or alkaline phosphatase levels exceeding 2.5 times the upper limit of the normal laboratory values), alcohol abuse ( $>30$ units/week) and CMR contraindications. The study consisted of two periods: the screening phase and a double- blind study period with a scheduled duration of 52 weeks. After the screening phase, eligible subjects were randomly assigned in a 1:1 ratio (using computer generated codes) to receive either daily therapy with $8 \mathrm{mg}$ of rosiglitazone or placebo. The treatment was titrated: during the first eight weeks, the participants were treated with one tablet daily (rosiglitazone $4 \mathrm{mg}$ or placebo), which was doubled after 8 weeks. Subsequently, all subjects were submitted to intensive lifestyle changes including a $1500 \mathrm{kCal}$ diet. In addition, the participants were motivated to increase their level of daily physical activity aiming at an extra energy-expenditure of 270 $\mathrm{kCal}$ per day (i.e. a normal-pace walk of 30 minutes, three times daily). All subjects were closely monitored during the study by the study physician and vascular nurse at $8,22,36$ and 52 weeks after randomization/ baseline. Hypertension was treated using a predefined protocol: first with salt restriction followed by step-up pharmacological therapy if needed, starting with hydrochlorothiazide $12.5 \mathrm{mg}$ followed by ACE inhibition.

From this original study population, 10 subjects from the placebo group and 10 subjects from the Rosiglitazone group were randomly selected (sample size calculation by Bellenger et al. [18]: using CMR, 9 subjects are needed to detect a $10 \mathrm{~g}$ change in LV mass with a power of $90 \%$ and an $\alpha$ error of 0.05 , corresponding with a $4.5 \mathrm{~g}$ change in LV mass-I [average body surface area 2.2]). These 20 subjects underwent a CMR examination at baseline to evaluate LV mass (primary endpoint), LV volumes and LV systolic function. Assessment of clinical measurements (body mass index, waist circumference, blood pressure) and laboratory measurements (triglycerides, high-density lipoprotein cholesterol [HDL cholesterol], total cholesterol, fasting blood glucose, glycated hemoglobin, insulin, high-sensitivity C-reactive protein [hs-CRP]) were performed just prior to CMR. Insulin resistance was calculated according to the homeostatic model assessment method (HOMA-IR) [20]. CMR examination, and clinical and laboratory measurements were repeated after one year. Approval by the local ethics committee and informed consent were obtained.

\section{CMR data acquisition}

CMR was performed on a 1.5T Gyroscan ACS-NT/ Intera MRI scanner (Philips Medical Systems, Best, The Netherlands) equipped with powertrack 6000 gradients and 5-element cardiac synergy coil.

For evaluation of LV mass, LV volumes and LV systolic function, the heart was imaged in short-axis view from apex to base, with 10-12 imaging levels (dependent on heart size) using an ECG-triggered balanced turbo field-echo sequence [21]. Typical parameters were a field of view of $400 \times 400 \mathrm{~mm}^{2}$, matrix of $256 \times 256$ 
pixels, slice thickness of $10.00 \mathrm{~mm}$, no slice gap, flip angle of $50^{\circ}$, time to echo of $1.82 \mathrm{~ms}$, and time to repeat of $3.65 \mathrm{~ms}$. Temporal resolution was 25 to $39 \mathrm{~ms}$.

\section{CMR data analysis}

Data were analyzed with MASS software developed at our institution (Medis, Leiden, the Netherlands). Analysis was performed by the same researcher (initials S.D.R.) with more than five years experience in CMR. To determine LV mass, LV systolic function and volumes, endocardial and epicardial borders were manually traced on the short-axis cine images. Papillary muscles were regarded as part of the ventricular cavity. LV mass, LV end-systolic volume (LV ESV), LV end-diastolic volume (LV EDV) and ejection fraction (EF) were assessed. LV mass, LV EDV and LV ESV were corrected for body surface area (yielding LV mass-I, LV EDV-I and LV ESV-I).

\section{Statistical analysis}

Continuous variables were tested for normal distribution (by evaluation of normal Q-Q plots of residuals obtained after correction for between group effects) and expressed as mean \pm standard deviation (SD) or median (interquartile range). Differences at baseline and at follow-up between groups (rosiglitazone vs. placebo group) were analyzed using the unpaired $t$-test, Mann-Whitney $U$-test (numerical data) or Fisher's exact test (categorical data) as appropriate. Variables at baseline were compared to follow-up using the paired $t$-test, Wilcoxon singed rank test (numerical data) or McNemar's test (categorical data). Changes in variables from baseline to follow-up between subjects who received rosiglitazone and placebo therapy were compared using the unpaired $t$-test or Mann-Whitney $U$-test. Non-normally distributed variables were log transformed for further analysis. Furthermore, the relation between the kind of therapy (rosiglitazone vs. placebo) and changes in LV mass-I (primary endpoint), and alterations in clinical and CMR variables between baseline and follow-up and changes in LV mass-I (primary endpoint) were evaluated. (Pearson's correlation coefficients ( $r$ ), p-values reported). Subsequently, variables with a significant relation or trend towards a significant relation with LV mass-I $(\mathrm{p}<0.10)$ were included in a multiple linear regression model to evaluate the relation between these variables and LV mass-I. Furthermore, in order to correct for possible differences in LV mass-I at baseline, we have included this variable in the multiple linear regression model.

\section{Results}

\section{Clinical and laboratory characteristics}

At baseline, no differences in clinical and laboratory variables were observed between subjects who were randomized for rosiglitazone or placebo therapy. Variables at baseline and follow-up for the subjects who received rosiglitazone therapy and subjects who received placebo therapy are presented in Table 1. For both groups, body mass index, waist circumference, systolic and diastolic blood pressure significantly decreased from baseline to follow-up. In the placebo group, no significant change was observed in laboratory variables, except for a decrease in insulin (from 11.5 (9.3) to 7.0 (5.8), p = 0.007) and HOMA-IR (from 1.6 (1.1) to $0.9(0.8), \mathrm{p}=$ $0.007)$. In the rosiglitazone group, the level of triglycerides, insulin, HOMA-IR and hs-CRP significantly decreased, whereas HDL cholesterol significantly increased.

\section{CMR variables}

Table 2 shows the CMR variables at baseline and followup for subjects who received rosiglitazone or placebo therapy in conjunction to lifestyle intervention, respectively. Except for LVEDV-I ( $91 \pm 12$ vs. $78 \pm 6 \mathrm{ml} / \mathrm{m}^{2}$, p $=0.007$, resp. rosiglitazone and placebo), CMR variables were similar between the two groups at baseline. LV mass-I at baseline was not significantly different between both groups $(\mathrm{p}=0.13)$. In both groups, LV EDV en LV ESV and LVEF did not significantly change between baseline and follow-up. Interestingly, no significant change in LV mass-I was observed in the rosiglitazone group $\left(54.7 \pm 9.9 \mathrm{~g} / \mathrm{m}^{2}\right.$ vs. $\left.53.7 \pm 9.2 \mathrm{~g} / \mathrm{m}^{2}, \mathrm{p}=0.3\right)$, whereas LV mass-I significantly decreased in the subjects who were treated with placebo therapy $\left(48.9 \pm 5.3 \mathrm{~g} / \mathrm{m}^{2}\right.$ vs. $\left.44.3 \pm 5.6 \mathrm{~g} / \mathrm{m}^{2}, \mathrm{p}<0.001\right)$. Accordingly, mean LV mass-I decreased $1.0 \pm 2.5 \mathrm{~g} / \mathrm{m}^{2}$ in the rosiglitazone group vs. $4.6 \pm 1.9 \mathrm{~g} / \mathrm{m}^{2}$ in the placebo group ( $\left.\mathrm{p}=0.002\right)$.

None of the alterations in clinical and laboratory variables during follow-up correlated significantly with the change in LV mass-I. Only a trend towards a significant correlation was observed between change in triglyceride, systolic and diastolic blood pressure between baseline and follow-up and reduction in LV mass-I $(r=-0.392, \mathrm{p}$ $=0.087, \mathrm{r}=-0.392, \mathrm{p}=0.087$ and $\mathrm{r}=-0.384, \mathrm{p}=0.095$, respectively).

The multiple linear regression models to assess the relative effect of rosiglitazone therapy, systolic and diastolic pressure and triglyceride on LV-mass-I are presented in Table 3. After correction for systolic and diastolic blood pressure and triglyceride, the kind of therapy (rosiglitazone vs. placebo) remained the only significant predictor of the extent of LV mass-I reduction. Also, after correction for LV mass-I at baseline, the kind of therapy remained the only significant predictor of LV mass-I reduction.

\section{Discussion}

The main findings in the current study are as follows: intensive lifestyle intervention including a diet and 
Table 1 Clinical and laboratory variables at baseline and follow-up

\begin{tabular}{|c|c|c|c|c|c|c|c|c|c|}
\hline \multirow[t]{2}{*}{ Clinical variables } & \multicolumn{3}{|c|}{ Rosiglitazone therapy } & \multicolumn{3}{|c|}{ Placebo therapy } & \multirow{2}{*}{$\begin{array}{l}\text { Rosiglitazone therapy } \\
\Delta \text { baseline-follow-up }\end{array}$} & \multicolumn{2}{|l|}{ Placebo therapy } \\
\hline & Baseline & Follow-up & P-value & Baseline & Follow-up & P-value & & $\Delta$ baseline-follow-up & P-value \\
\hline Age (yrs) & $60 \pm 6$ & $61 \pm 6$ & $<0.001$ & $57 \pm 5$ & $58 \pm 5$ & $<0.001$ & & & \\
\hline Body mass index $\left(\mathrm{kg} / \mathrm{m}^{2}\right)$ & $30.3 \pm 4.5$ & $28.7 \pm 4.8$ & 0.001 & $31.4 \pm 4.9$ & $29.2 \pm 3.8$ & 0.022 & $-1.6 \pm 1.0$ & $-2.2 \pm 2.5$ & 0.5 \\
\hline Waist circumference (cm) & $112 \pm 11$ & $104 \pm 14$ & 0.001 & $111 \pm 12$ & $102 \pm 10$ & 0.005 & $-8 \pm 5$ & $-8 \pm 7$ & 0.9 \\
\hline Systolic blood pressure (mmHg) & $154 \pm 23$ & $136 \pm 15$ & 0.021 & $149 \pm 14$ & $135 \pm 11$ & 0.001 & $-18 \pm 21$ & $-14 \pm 9$ & 0.6 \\
\hline Diastolic blood pressure $(\mathrm{mmHg})$ & $91 \pm 11$ & $78 \pm 8$ & 0.001 & $89 \pm 6$ & $78 \pm 5$ & $<0.001$ & $-13 \pm 9$ & $-11 \pm 5$ & 0.6 \\
\hline Antihypertensive drugs, N (\%) & $2(20)$ & $4(40)$ & 0.5 & $4(40)$ & $4(40)$ & 1.0 & & & \\
\hline \multicolumn{10}{|l|}{ Laboratory variables } \\
\hline Triglycerides (mmol/l) & $1.8 \pm 0.5$ & $1.4 \pm 0.3$ & 0.008 & $1.9 \pm 0.7$ & $1.7 \pm 0.6$ & 0.3 & $-0.4 \pm 0.4$ & $-0.2 \pm 0.5$ & 0.3 \\
\hline HDL cholesterol (mmol/l) & $1.2 \pm 0.2$ & $1.4 \pm 0.2$ & 0.002 & $1.2 \pm 0.2$ & $1.2 \pm 0.1 \dagger$ & 0.7 & $0.2 \pm 0.2$ & $0.02 \pm 0.2$ & 0.024 \\
\hline LDL cholesterol (mmol/l) & $3.8 \pm 0.8$ & $4.3 \pm 0.6$ & 0.079 & $3.9 \pm 0.4$ & $3.8 \pm 0.5$ & 0.7 & $0.6 \pm 0.9$ & $-0.06 \pm 0.4$ & 0.063 \\
\hline Total cholesterol (mmol/l) & $5.8 \pm 0.9$ & $6.3 \pm 0.7$ & 0.1 & $5.9 \pm 0.6$ & $5.8 \pm 0.6$ & 0.5 & $0.6 \pm 1.0$ & $-0.1 \pm 0.6$ & 0.075 \\
\hline Fasting blood glucose (mmol/l) & $5.0 \pm 0.6$ & $4.8 \pm 0.7$ & 0.098 & $5.7 \pm 1.0$ & $5.3 \pm 1.1$ & 0.071 & $-0.3 \pm 0.5$ & $-0.4 \pm 0.6$ & 0.6 \\
\hline HbA1c (\%) & $5.2 \pm 0.6$ & $5.3 \pm 0.4$ & 0.3 & $5.2 \pm 0.4$ & $5.3 \pm 0.3$ & 1.0 & $0.1 \pm 0.3$ & $0.0 \pm 0.4$ & 0.5 \\
\hline Insulin $(\mathrm{mmol} / \mathrm{l})^{*}$ & $11.5(11.3)$ & $6.0(4.3)$ & 0.034 & $11.5(9.3)$ & $7.0(5.8)$ & 0.007 & $-4.2 \pm 5.0$ & $-7.6 \pm 7.3$ & 0.3 \\
\hline $\mathrm{HOMA}-\mathrm{IR}(\mathrm{mmol} / \mathrm{l} \times \mathrm{mU} / \mathrm{l})^{*}$ & $1.5(1.5)$ & $0.6(0.5)$ & 0.021 & $1.6(1.1)$ & $0.9(0.8)$ & 0.007 & $-0.6 \pm 0.6$ & $-1.1 \pm 1.0$ & 0.2 \\
\hline hs-CRP $(\mathrm{mmol} / \mathrm{l})^{*}$ & $2.4(3.1)$ & $1.6(1.7)$ & 0.047 & $2.6(0.9)$ & $2.6(2.6)$ & 0.6 & $-1.7 \pm 2.5$ & $7.0 \pm 21.2$ & 0.2 \\
\hline
\end{tabular}

Data are expressed as mean $\pm \mathrm{SD}$. * Variables were non-normally distributed and therefore expressed as median (interquartile range); Mann-Whitney $U$ test or Wilcoxon singed rank test were used for comparison between groups and between baseline and follow-up, respectively.

$+\mathrm{p}<0.05$ between subjects who received Rosiglitazone or placebo therapy at follow-up.

HbA1c: glycated hemoglobin, HDL cholesterol: high-density lipoprotein cholesterol, HOMA-IR: homeostasis model assessment of insulin resistance (fasting blood glucose (mmol/l) $\times$ fasting insulin (mU/I)/22.5), hs-CRP: high-sensitivity C-reactive protein, LDL cholesterol: low-density lipoprotein cholesterol. 
Table 2 CMR variables at baseline and follow-up

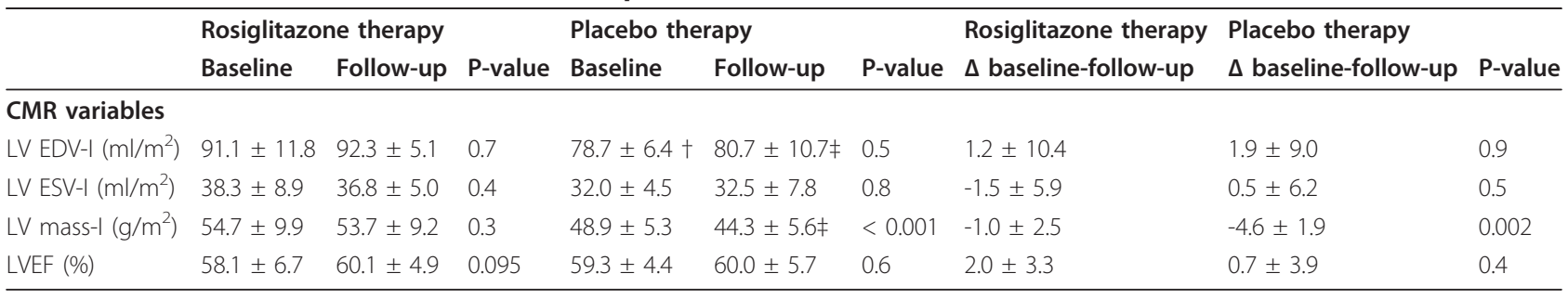

$\dagger \mathrm{p}<0.05$ between subjects who received rosiglitazone or placebo therapy at baseline.

$\neq \mathrm{p}<0.05$ between subjects who received rosiglitazone or placebo therapy at follow-up.

LV EDV-I: left ventricular end-diastolic volume indexed for body surface area, LV ESV-I: left ventricular end-systolic volume indexed for body surface area: LV mass-l: left ventricular mass indexed for body surface area, left ventricular, LVEF: left ventricular ejection fraction.

physical exercise in conjunction with either rosiglitazone or placebo therapy, improves clinical characteristics such as body mass index, waist circumference, diastolic and systolic blood pressure. Furthermore, lifestyle intervention in conjunction with rosiglitazone or placebo therapy results in a significant decrease in insulin and insulin resistance (HOMA-IR). Also, in subjects who were randomised for rosiglitazone therapy, a significant increase in HDL cholesterol and a decrease in triglyceride and hs-CRP was observed, whereas no change in these variables was observed in subjects who used placebo therapy. Interestingly, lifestyle intervention in conjunction with placebo therapy resulted in a reduction of LV mass-I, whereas in subjects who were randomised for rosiglitazone therapy, LV mass-I remained unchanged.

\section{Clinical variables}

All subjects in our study were submitted to lifestyle intervention including a diet and exercise, which resulted in reduction of body mass index and waist circumference. This lifestyle intervention also significantly lowered systolic and diastolic blood pressure regardless of therapy (rosiglitazone or placebo). It is well known that weight reduction lowers blood pressure [22-24]. Systemic reviews of studies evaluating the effect of rosiglitazone have indeed not found any beneficial effects of rosiglitazone on blood pressure, which is in line with the results of the present study $[5,25]$.

\section{Laboratory measurements}

In both groups, thus regardless of treatment, insulin levels and insulin resistance significantly improved during follow-up. A major contributor to the development of insulin resistance (and thus higher levels of insulin) is the overabundance of free fatty acids produced in adipose tissue [1]. These free fatty acids lead to higher glucose and insulin levels through different pathways. For instance, free fatty acids stimulate production of glucose by the liver and high levels of free fatty acids lead to reduction of insulin sensitivity by inhibition of insulinmediated glucose uptake in peripheral tissues [1].

Table 3 Multivariable association clinical and laboratory variables and LV mass-I reduction

\begin{tabular}{|c|c|c|c|c|c|}
\hline & & B-coefficient & P-value $^{a}$ & $\mathrm{R}^{2}$ & P-value $^{b}$ \\
\hline \multirow[t]{2}{*}{ Model 1} & & & & 0.421 & 0.002 \\
\hline & Rosiglitazone therapy & $3.6(1.5-5.7)$ & 0.002 & & \\
\hline \multirow[t]{5}{*}{ Model 2} & & & & 0.516 & 0.002 \\
\hline & Rosiglitazone therapy & $3.2(1.1-5.3)$ & 0.006 & & \\
\hline & $\Delta$ systolic blood pressure & $-0.03(-0.12-0.06)$ & 0.5 & & \\
\hline & $\Delta$ diastolic blood pressure & $-0.07(-0.27-0.12)$ & 0.4 & & \\
\hline & $\Delta$ triglyceride & $-0.68(-.2-1.8)$ & 0.6 & & \\
\hline \multirow[t]{6}{*}{ Model 3} & & & & 0.611 & 0.01 \\
\hline & Rosiglitazone therapy & $3.7(1.7-5.7)$ & 0.003 & & \\
\hline & $\Delta$ systolic blood pressure & $-0.01(-0.09-0.08)$ & 0.9 & & \\
\hline & $\Delta$ diastolic blood pressure & $-0.11(-0.29-0.07)$ & 0.3 & & \\
\hline & $\Delta$ triglyceride & $-1.0(-3.3-1.3)$ & 0.4 & & \\
\hline & LV mass-I at baseline & $-0.1(-0.2-0.3)$ & 0.2 & & \\
\hline
\end{tabular}

\footnotetext{
${ }^{a}$ Level of significance of the association between the separate components of the model and reduction in LV mass-I.

${ }^{b}$ Level of significance of the model.

LV mass-I: left ventricular mass indexed for body surface area
} 
Accordingly, weight loss (thus reduction of adipose tissue) will reduce insulin levels and insulin resistance. Results from large clinical trials indeed showed that lifestyle changes significantly reduced the incidence of diabetes [26,27]. Thiazolidinediones act as insulin sentitizers by multiple mechanisms and a previous study in non-diabetic insulin resistant individuals indeed demonstrated lower insulin and improvement of insulin resistance after rosiglitazone treatment [28]. In the current study, no additional effect of rosiglitazone on insulin and insulin resistance could be observed, stressing the highly beneficial effects of lifestyle intervention, overshadowing the possible effect of rosiglitazone on these parameters.

The finding that rosiglitazone increases HDL cholesterol is in accordance with previous clinical trials evaluating the effect of rosiglitazone on lipid profile in patients with type 2 diabetes, in which HDL cholesterol levels increased approximately 10 percent [29-31]. These studies also found an adverse effect on low-density lipoprotein (LDL) cholesterol levels after rosiglitazone therapy. Although no significant change could be observed in our study, LDL cholesterol levels indeed increased in patients using rosiglitazone therapy. In the group using rosiglitazone, a significant reduction in triglycerides was noted. Previous studies revealed controversial results on the effect of rosiglitazone on triglycerides; some studies showed a similar decrease in triglycerides as was observed in the current study, whereas others found no effect on triglyceride level $[30,32,33]$.

\section{Left ventricular mass}

Previous studies showed that subjects with the metabolic syndrome often present with increased LV mass (and LV hypertrophy) [10,11] The Framingham Heart Study evaluated LV mass using echocardiography and observed that increased LV mass is an independent predictor of clinical events such as heart failure, ischemia, ventricular arrhythmia, and sudden cardiac death [12]. Accordingly, reduction of LV mass is important for improvement of clinical outcome. Several studies reported that weight loss is associated with a reduction in LV mass [34-36]. A recent study by Rider et al. [35] evaluated obese patients who underwent bariatric surgery, and found a regression of LV hypertrophy in these patients. The results from the current study show LV mass-I significantly decreased in subjects who underwent extensive lifestyle intervention (resulting in weight reduction) in conjunction with placebo therapy. Accordingly, intensive lifestyle intervention including a diet and exercise results in reverse remodeling of the LV in subjects with the metabolic syndrome. However, the use of rosiglitazone may have inhibited this beneficial effect of lifestyle intervention, as LV mass-I remained unchanged in this group.

The effect of rosiglitazone therapy on LV mass has been studied in experimental and clinical setting, however revealing controversial results [13-17]. Evidence from experimental studies has shown that administration of thiazolidinediones might be associated with the development of LV hypertrophy $[14,37,38]$. Bell et al. [14] investigated the trophic effects of rosiglitazone on cardiomyocytes in an experimental in-vitro model and observed that rosiglitazone itself does not iniate cellular hypertrophy directly. However, their results might suggest that rosiglitazone in combination with growth-regulating factors may make a modest contribution to cardiac remodeling (hypertrophy). Duan et al. [38] studied the effect of rosiglitazone in cardiomyocyte-specific PPAR- $\gamma$ knock-out mouse model and in control mice and observed that rosiglitazone causes cardiac hypertrophy in both models, however more pronounced in the control mice, suggesting also a partially PPAR- $\gamma$ independent mechanism responsible for the hypertrophic effects. On the other hand, studies have reported that thiazolidinediones inhibit cardiac hypertrophy $[13,16]$. Asakawa et al. [13] evaluated the effect of thiazolidinediones in-vitro on cultured rat cardiac myocytes and invivo using mice (exposed to angiotensine II or pressure overload to induce hypertrophic remodeling) and observed that thiazolidinedione therapy inhibit cardiac hypertrophy.

Thus far, only few studies have evaluated the possible hypertrophic effect of thiazolidinediones in patients $[15,17]$. St. John Sutton et al. [17] studied patients with type 2 diabetes using echocardiography and demonstrated that long-term use of rosiglitazone is not associated with increase in LV mass (or functional impairment). Likewise, Ghazzi et al. [15] performed an echocardiographic study in patients with type 2 diabetes submitted to troglitazone therapy and could not observe an increase in LV mass either.

Accordingly, the current study is the first study that evaluated the effect of rosiglitazone therapy on LV mass-I in subjects with the metabolic syndrome using CMR and revealed that rosiglitazone inhibits the positive effects (of reverse remodeling) of intensive lifestyle intervention. Due to the observational character of this study, the underlying mechanism remains to be elucidated. Possible explanations maybe that the effect of rosiglitazone on cardiomyocytes might inhibit the process of reverse remodeling directly. Or, the concurrent hypertrophic effect of rosiglitazone may minimize the effect of reverse remodeling (reduction of LV mass) due to lifestyle intervention, resulting in unchanged LV mass. Besides a direct effect of rosiglitazone on 
cardiomyocytes, it is suggested that thiazolidinediones affect hemodynamics by increasing mechanical loading through different mechanisms: thiazolidinediones may increase cardiac output due to decreased afterload as a consequence of decreased peripheral resistance, and enhanced fluid retention leading to increased cardiac preload $[5,14]$. The effect of reverse remodeling (LV mass reduction) due to lifestyle intervention and the simultaneously occurring haemodynamic effects of rosiglitazone might cancel each other out.

In two patients from the group following rosiglitazone therapy, anti-hypertensive medication was initiated during the course of the study. Two other patients from this group were already treated with anti-hypertensive medication at baseline, as well as four patients from the placebo group. The fact that medication was initiated during the study in patients from the rosiglitazone group, would potentially imply additional LV mass reduction in this group. And since LV mass-I was not significantly different for these patients at follow-up, this observation may even add to the possible cancelling effect of rosiglitazone on reverse LV remodeling.

The fact that the previous clinical studies $[15,17]$ were not able to find an effect of thiazolidinedione on LV mass might be explained by the use of CMR, enabling highly accurate measurements of LV mass [18] in stead of echocardiography which is operator and acoustic window dependent [39].

During the past few years, the safety of rosiglitazone therapy has been a matter of debate. Nissen and Wolski [40] performed a meta-analysis to study the effect of rosiglitazone on cardiovascular morbidity and mortality and concluded that rosiglitazone therapy was associated with an increased risk of myocardial infarction. The recently published RECORD trial evaluated the effect of addition of rosiglitazone to glucose-lowering therapy and found an increased risk of heart failure in patients treated with rosiglitazone compared to controls, whereas the overall cardiovascular morbidity and mortality was similar [41]. The results of the current study, suggesting a hypertrophic effect of rosiglitazone, and the previously recognized relation between LV hypertrophy and cardiac events such as ischemia and heart failure [12], might add to the paradigm of sodium and water retention to explain the increased risk of these events in patients using rosiglitazone.

A limitation of the present study is the relatively small study population. However, the use of CMR allows for very accurate and reproducible measurements enabling significant reduction in sample size [18].

\section{Conclusion}

Intensive lifestyle intervention resulted in LV mass-I reduction in subjects with the metabolic syndrome, indicating reverse remodeling. However, rosiglitazone therapy may have inhibited this positive reverse remodeling (LV mass-I reduction).

\section{Acknowledgements}

None to declare.

\section{Authors' contributions}

SDR participated in the study design, carried out the data collection and analysis and drafted the manuscript; RAD participated in the study design and data collection; JJMW participated in the study design, data collection and analysis; HJL participated in the study design; BJAM participated in the study design and carried out the statistical analysis, JTT participated in the study design, AdR participated in the study design and interpretation of the results. All authors read and approved the final manuscript.

\section{Competing interests}

The authors declare that they have no competing interests.

Received: 6 April 2011 Accepted: 28 October 2011

Published: 28 October 2011

\section{References}

1. Eckel RH, Grundy SM, Zimmet PZ: The metabolic syndrome. Lancet 2005, 365:1415-1428.

2. Lakka HM, Laaksonen DE, Lakka TA, Niskanen LK, Kumpusalo $E$, Tuomilehto J, Salonen JT: The metabolic syndrome and total and cardiovascular disease mortality in middle-aged men. JAMA 2002, 288:2709-2716.

3. Malik S, Wong ND, Franklin SS, Kamath TV, L'Italien GJ, Pio JR, Williams GR: Impact of the metabolic syndrome on mortality from coronary heart disease, cardiovascular disease, and all causes in United States adults. Circulation 2004, 110:1245-1250.

4. Yki-Jarvinen $\mathrm{H}$ : Pathogenesis of non-insulin-dependent diabetes mellitus. Lancet 1994, 343:91-95.

5. Yki-Jarvinen H: Thiazolidinediones. N Engl J Med 2004, 351:1106-1118.

6. Berger J, Moller DE: The mechanisms of action of PPARs. Annu Rev Med 2002, 53:409-435.

7. Barbier O, Torra IP, Duguay Y, Blanquart C, Fruchart JC, Glineur C, Staels B: Pleiotropic actions of peroxisome proliferatoractivated receptors in lipid metabolism and atherosclerosis. Arterioscler Thromb Vasc Biol 2002, 22:717-726.

8. Willson TM, Lambert MH, Kliewer SA: Peroxisome proliferator-activated receptor gamma and metabolic disease. Annu Rev Biochem 2001, 70:341-367.

9. Kim SH, Abbasi F, Chu JW, McLaughlin TL, Lamendola C, Polonsky KS, Reaven GM: Rosiglitazone reduces glucose-stimulated insulin secretion rate and increases insulin clearance in nondiabetic, insulin-resistant individuals. Diabetes 2005, 54:2447-2452.

10. Burchfiel CM, Skelton TN, Andrew ME, Garrison RJ, Arnett DK, Jones DW, Taylor HA Jr: Metabolic syndrome and echocardiographic left ventricular mass in blacks: the Atherosclerosis Risk in Communities (ARIC) Study. Circulation 2005, 112:819-827.

11. Cuspidi C, Meani S, Fusi V, Severgnini B, Valerio C, Catini E, Leonetti G, Magrini F, Zanchetti A: Metabolic syndrome and target organ damage in untreated essential hypertensives. J Hypertens 2004, 22:1991-1998.

12. Levy D, Garrison RJ, Savage DD, Kannel WB, Castelli WP: Prognostic implications of echocardiographically determined left ventricular mass in the Framingham Heart Study. N Engl J Med 1990, 322:1561-1566.

13. Asakawa M, Takano H, Nagai T, Uozumi H, Hasegawa H, Kubota N, Saito T, Masuda $Y$, Kadowaki T, Komuro I: Peroxisome proliferator-activated receptor gamma plays a critical role in inhibition of cardiac hypertrophy in vitro and in vivo. Circulation 2002, 105:1240-1246.

14. Bell D, McDermott BJ: Effects of rosiglitazone and interactions with growth-regulating factors in ventricular cell hypertrophy. Eur J Pharmacol 2005, 508:69-76.

15. Ghazzi MN, Perez JE, Antonucci TK, Driscoll JH, Huang SM, Faja BW, Whitcomb RW: Cardiac and glycemic benefits of troglitazone treatment in NIDDM. The Troglitazone Study Group. Diabetes 1997, 46:433-439. 
16. Sakai S, Miyauchi T, Irukayama-Tomobe Y, Ogata T, Goto K, Yamaguchi I: Peroxisome proliferator-activated receptor-gamma activators inhibit endothelin-1-related cardiac hypertrophy in rats. Clin Sci (Lond) 2002, 103(Suppl 48):165-20S.

17. St John Sutton M, Rendell M, Dandona P, Dole JF, Murphy K, Patwardhan R, Patel J, Freed M: A comparison of the effects of rosiglitazone and glyburide on cardiovascular function and glycemic control in patients with type 2 diabetes. Diabetes Care 2002, 25:2058-2064.

18. Bellenger NG, Davies LC, Francis JM, Coats AJ, Pennell DJ: Reduction in sample size for studies of remodeling in heart failure by the use of cardiovascular magnetic resonance. J Cardiovasc Magn Reson 2000, 2:271-278

19. Alberti KG, Zimmet P, Shaw J: Metabolic syndrome-a new world-wide definition. A Consensus Statement from the International Diabetes Federation. Diabet Med 2006, 23:469-480.

20. Matthews DR, Hosker JP, Rudenski AS, Naylor BA, Treacher DF, Turner RC: Homeostasis model assessment: insulin resistance and beta-cell function from fasting plasma glucose and insulin concentrations in man. Diabetologia 1985, 28:412-419.

21. Roes SD, Kaandorp TA, Marsan NA, Westenberg JJ, Dibbets-Schneider $P$, Stokkel MP, Lamb HJ, van der Wall EE, de Roos A, Bax JJ: Agreement and disagreement between contrast-enhanced magnetic resonance imaging and nuclear imaging for assessment of myocardial viability. Eur I NuCl Med Mol Imaging 2009, 36:594-601.

22. Krousel-Wood MA, Muntner P, He J, Whelton PK: Primary prevention of essential hypertension. Med Clin North Am 2004, 88:223-238.

23. Franco V, Oparil S, Carretero OA: Hypertensive therapy: Part I. Circulation 2004, 109:2953-2958

24. Alderman MH: Non-pharmacological treatment of hypertension. Lancet 1994, 344:307-311.

25. Czoski-Murray C, Warren E, Chilcott J, Beverley C, Psyllaki MA, Cowan J: Clinical effectiveness and cost-effectiveness of pioglitazone and rosiglitazone in the treatment of type 2 diabetes: a systematic review and economic evaluation. Health Technol Assess 2004, 8(13):iii, ix-X,-1-91.

26. Knowler WC, Barrett-Connor E, Fowler SE, Hamman RF, Lachin JM, Walker EA, Nathan DM, Diabetes Prevention Program Research Group: Reduction in the incidence of type 2 diabetes with lifestyle intervention or metformin. N Engl J Med 2002, 346:393-403.

27. Diabetes Prevention Program Research Group, Knowler WC, Fowler SE, Hamman RF, Christophi CA, Hoffman HJ, Brenneman AT, Brown-Friday JO, Goldberg R, Venditti E, Nathan DM: 10-year follow-up of diabetes incidence and weight loss in the Diabetes Prevention Program Outcomes Study. Lancet 2009, 374:1677-1686.

28. Kim SH, Abbasi F, Chu JW, McLaughlin TL, Lamendola C, Polonsky KS, Reaven GM: Rosiglitazone reduces glucose-stimulated insulin secretion rate and increases insulin clearance in nondiabetic, insulin-resistant individuals. Diabetes 2005, 54:2447-2452.

29. Lebovitz HE, Dole JF, Patwardhan R, Rappaport EB, Freed MI, Rosiglitazone Clinical Trials Study Group: Rosiglitazone monotherapy is effective in patients with type 2 diabetes. J Clin Endocrinol Metab 2001, 86:280-288.

30. Fonseca V, Rosenstock J, Patwardhan R, Salzman A: Effect of metformin and rosiglitazone combination therapy in patients with type 2 diabetes mellitus: a randomized controlled trial. JAMA 2000, 283(13):1695-1702.

31. Deeg MA, Buse JB, Goldberg RB, Kendall DM, Zagar AJ, Jacober SJ, Khan MA, Perez AT, Tan MH, GLAI Study Investigators: Pioglitazone and rosiglitazone have different effects on serum lipoprotein particle concentrations and sizes in patients with type 2 diabetes and dyslipidemia. Diabetes Care 2007, 30:2458-2464.

32. Raskin P, Rendell M, Riddle MC, Dole JF, Freed MI, Rosenstock J, Rosiglitazone Clinical Trials Study Group: A randomized trial of rosiglitazone therapy in patients with inadequately controlled insulintreated type 2 diabetes. Diabetes Care 2001, 24:1226-1232.

33. Gómez-Perez FJ, Fanghänel-Salmón G, Antonio Barbosa J, MontesVillarreal J, Berry RA, Warsi G, Gould EM: Efficacy and safety of rosiglitazone plus metformin in Mexicans with type 2 diabetes. Diabetes Metab Res Rev 2002, 18:127-134

34. Viljanen AP, Karmi A, Borra R, Pärkkä JP, Lepomäki V, Parkkola R, Lautamäki R, Järvisalo $M$, Taittonen $M$, Rönnemaa T, lozzo P, Knuuti J, Nuutila P, Raitakari OT: Effect of caloric restriction on myocardial fatty acid uptake, left ventricular mass, and cardiac work in obese adults. Am J Cardiol 2009, 103:1721-1726.
35. Rider OJ, Francis JM, Ali MK, Petersen SE, Robinson M, Robson MD, Byrne JP, Clarke K, Neubauer S: Beneficial cardiovascular effects of bariatric surgical and dietary weight loss in obesity. J Am Coll Cardiol 2009, 54:718-726.

36. Hinderliter A, Sherwood A, Gullette EC, Babyak M, Waugh R, Georgiades A, Blumenthal JA: Reduction of left ventricular hypertrophy after exercise and weight loss in overweight patients with mild hypertension. Arch Intern Med 2002, 162:1333-1339.

37. Stephens TW, Bergman JA, Bue-Valleskey JM, DiMarchi RD, Slieker JL, Tinsley FC, Williams GD: Thiazolidinedione induced cardiac biochemical changes and increased IGF-1 action on cardiomyocytes. Diabetologia 1995, 38:A200

38. Duan SZ, Ivashchenko CY, Russell MW, Milstone DS, Mortensen RM: Cardiomyocyte-specific knockout and agonist of peroxisome proliferator-activated receptor-gamma both induce cardiac hypertrophy in mice. Circ Res 2005, 97:372-379.

39. Allison JD, Flickinger FW, Wright JC, Falls DG, Prisant LM, VonDohlen TW, Frank MJ: Measurement of left ventricular mass in hypertrophic cardiomyopathy using MRI: comparison with echocardiography. Magn Reson Imaging 1993, 11:329-334.

40. Nissen SE, Wolski K: Effect of rosiglitazone on the risk of myocardial infarction and death from cardiovascular causes. N Engl J Med 2007, 356:2457-2471.

41. Home PD, Pocock SJ, Beck-Nielsen H, Curtis PS, Gomis R, Hanefeld M, Jones NP, Komajda M, McMurray JJ, RECORD Study Team: Rosiglitazone evaluated for cardiovascular outcomes in oral agent combination therapy for type 2 diabetes (RECORD): a multicentre, randomised, openlabel trial. Lancet 2009, 373:2125-2135.

doi:10.1186/1532-429X-13-65

Cite this article as: Roes et al:: Effect of lifestyle intervention plus rosiglitazone or placebo therapy on left ventricular mass assessed with cardiovascular magnetic resonance in the metabolic syndrome. Journal of Cardiovascular Magnetic Resonance 2011 13:65.

\section{Submit your next manuscript to BioMed Central and take full advantage of:}

- Convenient online submission

- Thorough peer review

- No space constraints or color figure charges

- Immediate publication on acceptance

- Inclusion in PubMed, CAS, Scopus and Google Scholar

- Research which is freely available for redistribution

Submit your manuscript at www.biomedcentral.com/submit
C BioMed Central 